\title{
X-linked adrenal hypoplasia congenita: clinical and follow-up findings of two kindreds, one with a novel NROB 1 mutation
}

Bernardo Dias Pereira', Iris Pereira², Jorge Ralha Portugal',

João Gonçalves², Luísa Raimundo'

\begin{abstract}
SUMMARY
X-linked adrenal hypoplasia congenita typically manifests as primary adrenal insufficiency in the newborn age and hypogonadotropic hypogonadism in males, being caused by mutations in NROB1 gene. We present the clinical and follow-up findings of two kindreds with NROB1 mutations. The proband of kindred $A$ had a diagnosis of primary adrenal insufficiency when he was a newborn. Family history was relevant for a maternal uncle death at the newborn age. Beyond 2 year-old steroid measurements rendered undetectable and delayed bone age was noticed. Molecular analysis of NROB1 gene revealed a previously unreported mutation (c.1084A $>T$ ), leading to a premature stop codon, p.Lys $362 *$, in exon 1. His mother and sister were asymptomatic carriers. At 14 year-old he had $3 \mathrm{~mL}$ of testicular volume and biochemical surveys ( $\mathrm{LH}<0.1 \mathrm{UI} / \mathrm{L}$, total testosterone $<10 \mathrm{ng} / \mathrm{dL}$ ) concordant with hypogonadotrophic hypogonadism. Kindred B had two males diagnosed with adrenal insufficiency at the newborn age. By 3 year-old both siblings had undetectable androgen levels and delayed bone age. NROB1 molecular analysis identified a nonsense mutation in both cases, c.243C>G; p.Tyr81*, in exon 1. Their mother and sister were asymptomatic carriers. At 14 year-old (Tanner stage 1) hypothalamic-pituitary-gonadal axis evaluation in both males $(\mathrm{LH}<0.1 \mathrm{UI} / \mathrm{L}$, total testosterone $<10$ $\mathrm{ng} / \mathrm{dL}$ ) confirmed hypogonadotropic hypogonadism. In conclusion, biochemical profiles, bone age and an X-linked inheritance led to suspicion of NROB1 mutations. Two nonsense mutations were detected in both kindreds, one previously unreported (c.1084A>T; p.Lys362*). Mutation identification allowed the timely institution of testosterone in patients at puberty and an appropriate genetic counselling for relatives. Arch Endocrinol Metab. 2015;59(2):181-5
\end{abstract}

Serviço de Endocrinologia e

Diabetes, Hospital Garcia de Orta - E.P.E., Almada-Setúbal, Portugal 2 Departamento de Genética Humana, Instituto Nacional de Saúde Dr. Ricardo Jorge, Lisboa, Portugal

Correspondence to: Bernardo Dias Pereira Serviço de Endocrinologia e Diabetes, $8^{\circ}$ piso,

Hospital Garcia de Orta, E.P.E. Av. Torrado da Silva, 2801-951 Almada-Setúbal

bern1981@gmail.com

Received on Feb/15/2014 Accepted on Jun/30/2014

DOI: $10.1590 / 2359-3997000000032$

\section{INTRODUCTION}

$\mathrm{X}$ -linked adrenal hypoplasia congenita (AHC; OMIM: 300200) is a rare disorder characterized by the lack of the permanent adrenal cortical zone ( 1 ), representing $0,97 \%$ of all causes of primary adrenal insufficiency (PAI) under age 18 (2). It usually manifests as severe PAI in a bimodal fashion (5-60 days and 2-13 years) (3) and hypogonadotropic hypogonadism $(\mathrm{HH})$ in males at the expected time of puberty (4). It is caused by mutations in NROBI (Nuclear Receptor subfamily 0 , group $\mathrm{B}$, member $\mathrm{I}$; also know as Dosage-sensitive sex reversal, adrenal hypoplasia congenita, critical region on chromosome $\mathrm{X}$, gene $\mathrm{l}, D A X-1)$, a gene encoding an orphan nuclear receptor expressed in hypothalamus, pituitary, adrenal gland and gonads, as well as in other tissues (5).

Herein we present two kindreds with NROBI mutations, one previously unreported, and a brief review of the literature regarding X-linked AHC.

\section{CLINICAL CASES}

Kindred A. A newborn male presented to the Emergency Department (ED) at 18 days of life with vomits, anorexia and generalized hypotony. He was born at 41 weeks of an uneventful pregnancy. Family history was remarkable for a premature death of an uncle (4 days of life, unknown cause). Physical examination revealed dehidratation and hyperpigmentation of axilae, areola and scrotum. Biochemical findings of hypoglycaemia (63 $\mathrm{mg} / \mathrm{dL})$ and altered electrolytes $\left(\mathrm{Na}^{+}: 117 \mathrm{mEq} / \mathrm{L} ; \mathrm{K}^{+}\right.$: $7.9 \mathrm{mEq} / \mathrm{L}$ ) prompted empirical treatment with glucocorticoids due to suspected PAI. Hormonal assays revealed elevated ACTH and androstenedione (Table 1), and the patient was referred to our department with a diagnosis of congenital adrenal hyperplasia $(\mathrm{CAH})$ based on non age-adjusted levels of 11-deoxycortisol (adult reference: $<1 \mathrm{ng} / \mathrm{mL}$ ). However, follow-up appointments revealed a gradual and atypical decrease of androgen levels to below the analytic sensitivity of the 
assays with mean doses of hydrocortisone of $19.5 \mathrm{mg} / \mathrm{m}^{2}$ (Figure 1A). Delayed bone age (2 yo; chronologic age: 2.9 yo) was also documented. Linking together, these surveys led to the hypothesis of a misdiagnosis of $\mathrm{CAH}$. A short Synacthen ${ }^{\circledR}$ test also failed to rise 11-deoxycortisol or 17-OHP levels (Table 2), excluding $\mathrm{CAH}$ and raising the suspicion for X-linked AHC. After approval by the local ethics committee and informed consent had been obtained from parents, molecular analysis of the NROBI gene was carried out, which revealed a c. $1084 \mathrm{~A}>\mathrm{T}$ mutation leading to a premature stop co-

Table 1. Probands of kindreds A and B: basal endocrinological surveys ${ }^{\dagger}$

\begin{tabular}{|c|c|c|}
\hline Kindred & A & B \\
\hline Age of the proband & 19 days & 6 months \\
\hline Parameters & \multicolumn{2}{|c|}{ Value [reference (6)] } \\
\hline 17-OHP (ng/mL) & $3.3[1.6-9.6]$ & 5 [0.2-3] \\
\hline 11-deoxycortisol (ng/mL) & 28.9 [21.1-93.2] & $3.9[1.37-11]$ \\
\hline Androstenedione (ng/mL) & $7.2[0.05-2.6]$ & $1.45[0.1-3]$ \\
\hline Cortisol (mcg/dL) & $8[1.5-30.4]$ & $23[1.2-35.9]$ \\
\hline Plasma renin activity (ug/L/h) & * & $59.9[2.4-37]$ \\
\hline ACTH $(\mathrm{pg} / \mathrm{mL})$ & $156.8[<50]$ & $878.2[<50]$ \\
\hline
\end{tabular}

${ }^{\dagger}$ Glucocorticoid withdrawal therapy period: proband of kindred $A-0.5$ days; proband of kindred $\mathrm{B}-1.5$ days. don (p.Lys362*) in exon 1 (Figure 2A). His mother and sister were asymptomatic carriers, whereas his maternal aunt had the wild type allele. This mutation, not previously described, gives rise to a premature stop codon, probably leading to a non-functional truncated protein.

From 6.8 to 13.9 yo his height curve crossed from $-0.03 \mathrm{SD}$ to $-1.79 \mathrm{SD}$ and testicular volume $(3 \mathrm{~mL})$ at 14 yo confirmed the clinical diagnosis of delayed puberty. Gonadotropins $(\mathrm{LH}<0.1 \mathrm{UI} / \mathrm{L})$ and total testosterone (TT) levels $(<10 \mathrm{ng} / \mathrm{dL})$ were also prepubertal. Testosterone replacement therapy $(100 \mathrm{mg} /$ month, IM) was started and at 17.6 yo the patient achieved a height $(167.3 \mathrm{~cm},-1.35 \mathrm{SD})$ close to his target height $(173.5 \mathrm{~cm})$.

Table 2. Cosyntropin stimulation test ${ }^{\dagger}$ in probands of kindreds $A$ and $B$

\begin{tabular}{lcccccc}
\hline Parameters & \multicolumn{2}{c}{$\begin{array}{c}\text { 11-deoxycortisol } \\
\text { (ng/mL) }\end{array}$} & \multicolumn{2}{c}{$\begin{array}{c}\mathbf{1 7 - 0 H P} \\
\text { (ng/mL) }\end{array}$} & \multicolumn{2}{c}{$\begin{array}{c}\text { Cortisol } \\
\text { (mcg/dL) }\end{array}$} \\
\hline Kindred (proband) & $\mathrm{A}$ & $\mathrm{B}$ & $\mathrm{A}$ & $\mathrm{B}$ & $\mathrm{A}$ & $\mathrm{B}$ \\
Basal & $<1.5$ & 0.4 & $<0.1$ & 4.9 & $<1$ & 23 \\
$30^{\prime}$ & $<1.5$ & 0.25 & $<0.1$ & 3.9 & $<1$ & 23 \\
$60^{\prime}$ & $<1.5$ & 0.4 & $<0.1$ & 2.2 & $<1$ & 22.3 \\
\hline
\end{tabular}

${ }^{\dagger}$ Glucocorticoid withdrawal therapy period: 1 day.
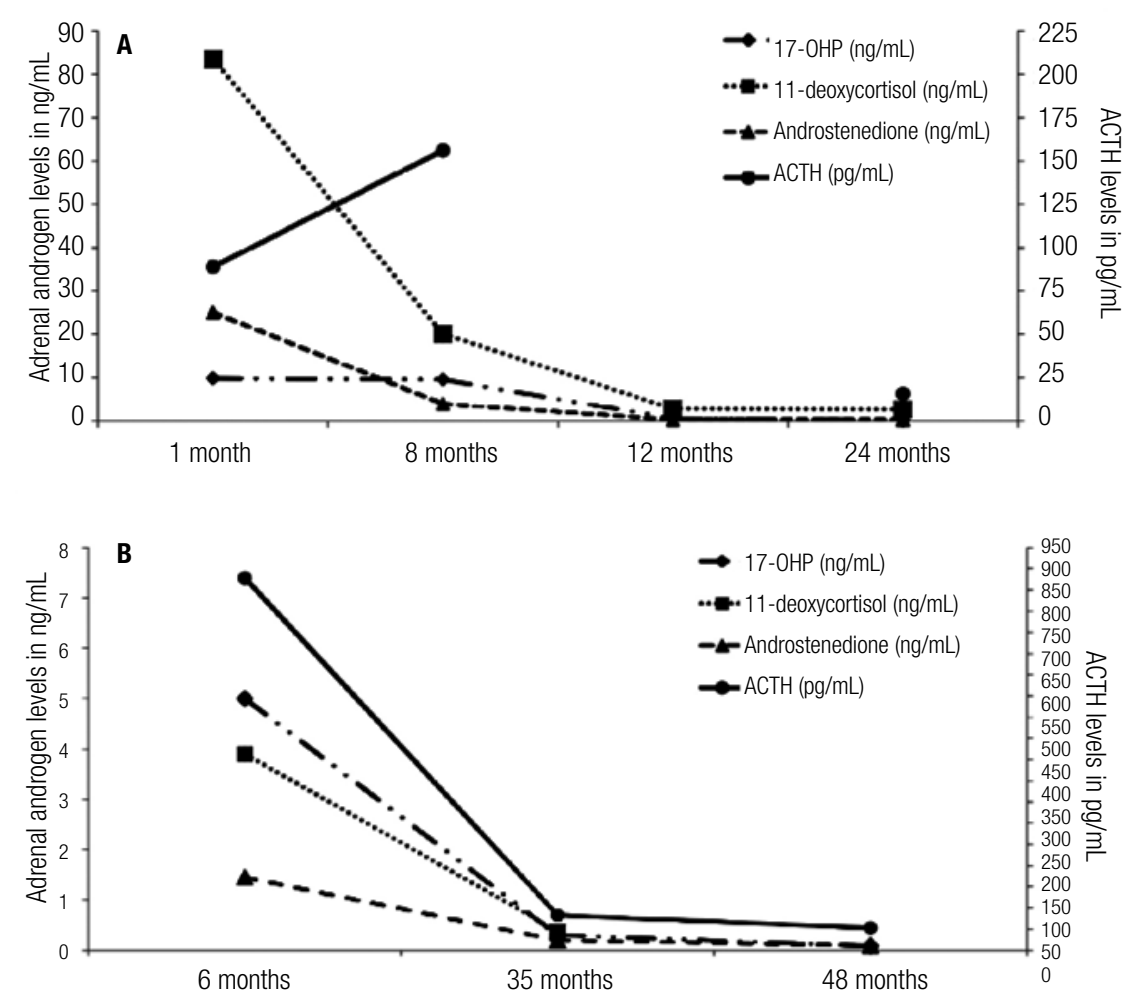

Figure 1. Serial basal measurements of steroids and ACTH: proband of kindred A over 24 months $(\mathbf{A})$ and proband of kindred B over 48 months (B). 


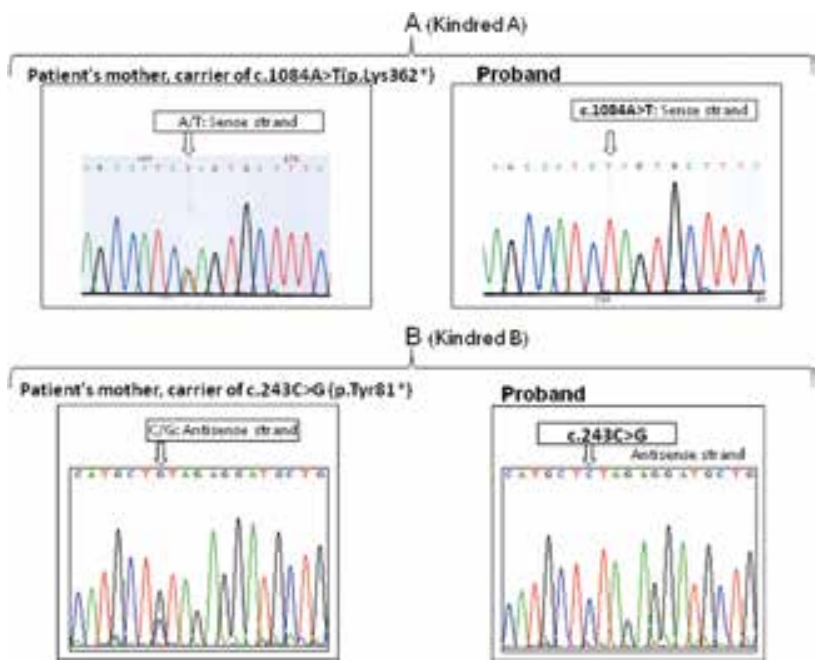

Figure 2. NROB1 sequencing results of the two probands and their mother's.

Kindred B. A Caucasian male presented to the ED at day $14^{\text {th }}$ of life with failure to thrive $(-12.5 \%$ of birth weight). He was the first of 4 children ( 3 males, 1 female) and was born after 38 weeks of a healthy pregnancy. No relevant family history was perceived. Hypoglycaemia $(64 \mathrm{mg} / \mathrm{dL})$, low sodium $(121 \mathrm{mEq} / \mathrm{L})$ and high potassium $(8.8 \mathrm{mEq} / \mathrm{L})$ led to a presumptive diagnosis of PAI, which was treated accordingly. At 6 months of age the patient was referred to our department with a diagnosis of $\mathrm{CAH}$ based on an elevated 17-OHP (Table 1), but a short Synacthen ${ }^{\circledR}$ test failed to further increase 17-OHP levels (Table 2). In addition, the androgen levels in the follow-up appointments rendered easily undetectable with mean doses of hydrocortisone of $16.5 \mathrm{mg} / \mathrm{m}^{2}$ (Figure 1B). Delayed bone age (2.5 yo; chronologic age: 3 yo) was also noticed, reinforcing the need to seek for other causes of PAI.

The third child of this family was a full term male who had a clinical diagnosis of PAI at 16 days of life. Hormonal surveys revealed elevated 17-OHP (16.8 $\mathrm{ng} / \mathrm{mL}$, reference for age: 1.6-9.6) and a diagnosis of $\mathrm{CAH}$ was established before reference to our department. During childhood, however, several admissions to the ED due to intercurrent illnesses revealed a consistently elevated ACTH $(1.133 \mathrm{pg} / \mathrm{mL})$ with undetectable steroid levels $(17-\mathrm{OHP}<0.1 \mathrm{ng} / \mathrm{mL}$; androstenedione $<0.2 \mathrm{ng} / \mathrm{mL}$; dehydroepiandrosterone-sulphate $<10 \mathrm{ug} / \mathrm{dL}$ ). At this stage, clinical data of both siblings raised the suspicion of a X-linked mutation of NROBI. After obtaining institutional ethics approval and written consent from their parents, molecular analysis allowed the identification of the nonsense mutation c.243C $>\mathrm{G}$
(p.Tyr81*) in exon 1 (Figure 2B), present in the two affected males. This mutation also gives rise to a premature stop codon and to a non-functional truncated protein. Their mother and sister were asymptomatic carriers.

At the expected time of puberty the 2 affected males had growth velocities of $3.8 \mathrm{~cm} /$ year $(-3.4 \mathrm{SD}$, proband at 13.4 yo) and $1.99 \mathrm{~cm} /$ year $(-4.89 \mathrm{SD}$, affected sibling at 13.6 yo) and testicular volumes of $2 \mathrm{~mL}$. Both HPG axis evaluations revealed concordant low basal LH $(<0.1 \mathrm{UI} / \mathrm{L})$ and TT $(<10 \mathrm{ng} / \mathrm{dL})$. After initiation of testosterone replacement therapy, a marked raise of growth velocity (proband at 15.3 yo: $9.1 \mathrm{~cm}, 1.96 \mathrm{SD}$; affected sibling at 14.6 yo: $8.7 \mathrm{~cm}$, $1.55 \mathrm{SD})$ was noticed, leading to presently height statures (target height: $170.5 \mathrm{~cm}$ ) of $167 \mathrm{~cm}$ (proband, 18.3 yo: $-1.42 S D$ ) and $165.6 \mathrm{~cm}$ (affected brother, 15.2 yo: $0.13 \mathrm{SD})$.

\section{DISCUSSION}

Since the first description of NROBI mutations as the genetic aetiology of X-linked AHC (1), more than 100 mutations have been reported in the literature. Most of them are nonsense or frameshift mutations that generate premature stop codons and truncated proteins (7-8). The evidence shows that NROBI acts mainly through a repressive modulation of NR5AI (Nuclear Receptor subfamily 5 , group A, member 1 ; also known as Steroidogenic Factor 1, SF-1), a gene with an essential role in the development of both the hypothalamic-pituitaryadrenocortical (HPA) and hypothalamic-pituitary-gonadal (HPG) axis. Although this modulation seems paradoxical, current models of adrenal gland development suggest that NR $5 A 1$ acts on the differentiation of deep mature cortex layers (where NROBI is underexpressed), whereas in the more superficial cortical strata NROBI expression, along with NR5Al and other molecular signals, maintains pluripotency of precursor cells and so the continuous external to internal development of the adrenal gland. The disruption of this molecular coordination would then impair its development (5).

In HPG axis the mechanism by which NROBI gene disruption leads to $\mathrm{HH}$ is also not well clarified (5). To date, the evidence shows that mutations in NROBI have negative effects at both hypothalamic and pituitary levels, as shown in dynamic studies of HPG axis (9). At the gonadal level, targeted disruption of NROBI in mice leads to testis digenesis and to severely compro- 
mised spermatogenesis, showing its importance in the development of the gonads (5).

Our cases reflect the classical and most severe form of X-linked AHC. At diagnosis, the presentation is indistinguishable from the more common $\mathrm{CAH}$, and it is frequent to misdiagnose patients as having this disorder until evidence of delayed puberty, when X-linked AHC is usually considered $(5,10)$. The suspicion of an NROBI mutation in the kindreds herein reported was based on a combination of an apparent X-linked pattern of inheritance, decreasing androgen levels over the first years of life and delayed bone age. This set of clinical data was extremely useful in excluding the diagnosis of $\mathrm{CAH}$, as this latter pathologic condition is characterized by an autosomal recessive pattern of transmission, elevated androgen levels and advanced bone age (11). Nevertheless, clinicians should be aware of the possible pitfalls during the diagnostic approach of $\mathrm{X}$-linked AHC. Firstly, besides the typical presentation of this disorder, it is also characterized by a significant phenotypic variability. Later childhood presentations (e.g., 7-8 yo) or transitorily compensated forms (from 2 to 12 years) can coexist within the same family with the more severe neonatal phenotypes $(3,5,10,12)$. Additionally, late-onset (20-28 yo) PAI (13-15), female presentations (16-18) or only mineralocorticoid deficiency (19) have also been reported. Thus, it is of paramount importance to be aware that NROBI mutations can manifest with these atypical phenotypes, which should not preclude the diagnosis. Interestingly, although genotype-phenotype correlations are characteristically absent in X-linked AHC, mutations in NROBI gene that maintains a partial repressor activity are usually consistent with more mild phenotypes, as a compensated adrenal insufficiency until adulthood $(13,15)$.

Secondly, as illustrated in our patients, elevated steroid levels at presentation can also lead to a misdiagnosis of CAH. Normal to high levels (e.g. 11-deoxicortisol) of androgens and cortisol can be present in the first months of life (usually 6 months postnatal) as a hallmark of persistent fetocortex activity (5). However, as shown in both kindreds, cosyntropin administration usually fails to significantly raise steroid precursors or cortisol (20) and serial basal measurements over time typically reveal a progressive decrease in androgens to undetectable levels (4), given the natural involution of foetal cortex. Additionally, appropriate assays should be selected to avoid falsely elevated hormone levels, as cross-reactions with other abundant fetocortical steroi- ds can occur with some of the available measurement methods (4).

In the differential diagnosis of X-linked AHC, besides $\mathrm{CAH}$, some authors have reported that, when other disorders have been excluded in a male infant (metabolic - Zellweger or Wolman - syndromes, adrenal haemorrhage) or in an older child (autoimmune disease, $\mathrm{X}$-linked adrenoleukodistrophy, Triple A syndrome, infection), it can be valuable to test for NROBI mutations, where its prevalence can reach to $58 \%(3)$.

Making a diagnosis of a NROBI mutation has several important implications. First, genetic testing for NROB1 mutations can be offered to potential carrier mothers and their female offspring before fertile ages, as early diagnosis and neonatal institution of salvage therapy in affected male newborns can prevent significant morbidity or death (12). Second, the clinician can suitably inform parents that $\mathrm{HH}$ will almost certainly arise in their affected child and discuss with them the available treatments and the appropriate age at which they should be initiated (21-22). Taking our kindreds as an example, the early diagnosis of X-linked AHC allowed the timely institution of testosterone when delayed puberty ensued, leading to improved final heights. Third, it also allows clarifying parent's expectations related with fertility of their male offspring, which in X-linked AHC almost always carries a poor prognosis. These patients usually have severe oligospermia and disorganized seminiferous structures at histopathology, and attempts to achieve fertility have often proved unsuccessful $(5,14,23)$. Nevertheless, a previous report has shown hopeful results with testicular sperm extraction and intracytoplasmatic injection treatments (24).

In summary, we reported two kindreds with X-linked AHC, one of them with a previously unreported NROBI mutation. We also highlighted some challenging aspects of its differential diagnosis, as well as the importance of establishing a correct diagnosis for a suitable genetic counselling and appropriate management of affected members.

Financial statement: none to declare.

Disclosure: no potential conflict of interest relevant to this article was reported.

\section{REFERENCES}

1. Zanaria E, Muscatelli F, Bardoni B, Strom TM, Guioli S, Guo W, et al. An unusual member of the nuclear hormone receptor su- 
perfamily responsible for $\mathrm{X}$-linked adrenal hypoplasia congenita. Nature. 1994;372:635-41.

2. Perry R, Kecha O, Paquette J, Celine H, Van Vliet G, Deal C. Primary adrenal insufficiency in children: twenty years experience at the Sainte-Justine Hospital, Montreal. J Clin Endocrinol Metab. 2005;90:3243-50.

3. Lin L, GuWX, Ozisik G, To WS, Owen CJ, Jameson JL, et al. Analysis of DAX1 (NR0B1) and steroidogenic factor-1 (NR5A1) in children and adults with primary adrenal failure: ten years' experience. J Clin Endocrinol Metab. 2006;91(8):3048-54.

4. Peter M, Viemann M, Partsch CJ, Sippell W. Congenital adrenal hypoplasia: clinical spectrum, experience with hormonal diagnosis, and report on new point mutations of the NROB1 gene. J Clin Endocrinol Metab. 1998;83:2666-74.

5. Jadhav U, Harris R, Jameson J. Hypogonadotropic hypogonadism in subjects with DAX1 mutations. Mol Cell Endocrinol. 2011;346(1-2):65-73.

6. Garagorri JM, Rodriguez G, Lario-Elboj AJ, Olivares JL, LarioMunoz A, Orden I. Reference levels for 17-hydroxyprogesterone, 11-desoxycortisol, cortisol, testosterone, dehydroepiandrosterone sulfate and androstenedione in infants from birth to six months of age. Eur J Pediatr. 2008;167:647-53.

7. Li N, Lui R, Zhang H, Yang J, Sun S, Zhang M, et al. Seven novel DAX1 mutations with loss of function identified in Chinese patients with congenital adrenal hypoplasia. J Clin Endocrinol Metab. 2010;95:E104-11.

8. Krone N, Riepe F, Dorr H, Morlot M, Rudorff K, Drop S, et al. Thirteen novel mutations in the NROB1 (DAX1) gene as cause of adrenal hipoplasia congenita. Hum Mutat. 2005;25:502-3.

9. Habiby R, Boepple P, Nachtigall L, Sluss P, Crowley W, Jameson J. Adrenal hipoplasia congenita with hypogonadotropic hypogonadism: evidence that NROB1 mutations lead to combined hypothalmic and pituitary defects in gonadotropin production. J Clin Invest. 1996;98:1055-62.

10. Reutens $A$, Achermann J, Ito $M$, Ito $M, G u$ W, Habiby $R$, et al. Clinical and functional effects of mutations in the nr0b1 gene in patients with adrenal hypoplasia congenita. J Clin Endocrinol Metab. 1999;84:504-11.

11. Miller W. The Adrenal Cortex and its Disorders. In: Brook C, Clayton P, Rosalind S, Editors. Brook's Clinical Pediatric Endocrinology. West Sussex: Wiley-Blackwell; 2009. p. 303-5.

12. Ostermann $S$, Salvi R, Lang-Muritano M, Voirol MJ, Rudolf Puttinger R, Gaillard R, et al. Importance of genetic diagnosis of NR0B1 deficiency: example from a large, multigenerational family. Horm Res. 2006;65:163-8.
13. Mantovani G, Ozisik G, Achermann JC, Romoli R, Borretta G, Persani $L$, et al. Hypogonadotropic hypogonadism as a presenting feature of late-onset $X$-linked adrenal hypoplasia congenita. J Clin Endocrinol Metab. 2002;87:44-8.

14. Tabarin A, Achermann JC, Recan D, Bex V, Bertagna X, ChristinMaitre $S$, et al. A novel mutation in DAX1 causes delayed onset adrenal insufficiency and incomplete hypogonadotropic hypogonadism. J Clin Invest. 2000;105:321-8.

15. Ozisik G, Mantovani G, Achermann JC, Persani L, Spada A, Weiss $\mathrm{J}$, et al. An alternate translation initiation site circumvents an amino-terminal DAX1 nonsense mutation leading to a mild form of X-linked adrenal hipoplasia congenita. J Clin Endocrinol Metab. 2008;88:417-23.

16. Merke D, Tajima T, Baron J, Cutler G. Hypogonadotropic hypogonadism in a female caused by an $\mathrm{X}$-linked recessive mutation in the DAX1 gene. N Engl J Med. 1999;340:1248-52.

17. Seminara S, Achermann J, Genel M, Jameson J, Crowley W Jr. $\mathrm{X}$-linked adrenal hypoplasia congenita: a mutation in DAX1 expands the phenotypic spectrum in males and females. J Clin Endocrinol Metab. 1999;84:4501-9.

18. Bernard P, Ludbrook L, Queipo G, Dinulos MB, Kletter GB, Zhang $\mathrm{YH}$, et al. A familial missense mutation in the hinge region of DAX1 associated with late-onset AHC in a prepubertal female. Mol Genet Metab. 2006;88:272-9.

19. Verrijn Stuart AA, Ozisik G, de Vroede MA, Giltay JC, Sinke RJ, Peterson TJ, et al. An amino-terminal DAX1 (NROB1) missense mutation associated with isolated mineralocorticoid deficiency. J Clin Endocrinol Metab. 2007;92(3):755-61.

20. Nakae J, Abe S, Tajima T, Shinohara N, Murashita M, Igarashi $Y$, et al. Three novel mutations and a de novo deletion mutation of the DAX-1 gene in patients with X-linked adrenal hypoplasia congenita. J Clin Endocrinol Metab. 1997;82:3835-41.

21. Dattani MT,Tziaferi V, Hindmarsh P. Evaluation of Disordered Puberty. In: Brook C, Clayton P, Rosalind S, Editors. Brook's Clinical Pediatric Endocrinology. West Sussex: Wiley-Blackwell; 2009. p. 213-38.

22. Loke KY, Larry KS, Lee YS, Peter M, Drop SL. Prepubertal diagnosis of $X$-linked congenital adrenal hypoplasia presenting after infancy. Eur J Pediatr. 2000;159(9):671-5.

23. Mantovani G, De Menis E, Borretta G, Radetti G, Bondioni S, Spada $A$, et al. DAX1 and X-linked adrenal hipoplasia congenita: clinical and molecular analysis in five patients. Eur J Endocrinol. 2006;154:685-9.

24. Frapsauce $C$, Ravel $C$, Legendre $M$, Sibony M, Mandelbaum J, Donadille B, et al. Birth afterTESE-ICSI in a man with hypogonadotropic hypogonadism and congenital adrenal hypoplasia linked to a DAX-1 (NR0B1) mutation. Hum Reprod. 2011;26(3):724-8. 